\title{
WNT signaling regulates self-renewal and differentiation of prostate cancer cells with stem cell characteristics
}

\author{
Isabelle Bisson $^{1}$, David M Prowse ${ }^{1}$ \\ ${ }^{I}$ Institute of Cancer, Bart's and The London School of Medicine and Dentistry, Queen Mary University of London, London EC1M \\ $6 B Q, U K$
}

Prostate cancer cells with stem cell characteristics were identified in human prostate cancer cell lines by their ability to form from single cells self-renewing prostaspheres in non-adherent cultures. Prostaspheres exhibited heterogeneous expression of proliferation, differentiation and stem cell-associated makers CD44, ABCG2 and CD133. Treatment with WNT inhibitors reduced both prostasphere size and self-renewal. In contrast, addition of Wnt3a caused increased prostasphere size and self-renewal, which was associated with a significant increase in nuclear $\beta$-catenin, keratin 18, CD133 and CD44 expression. As a high proportion of LNCaP and C4-2B cancer cells express androgen receptor we determined the effect of the androgen receptor antagonist bicalutamide. Androgen receptor inhibition reduced prostasphere size and expression of PSA, but did not inhibit prostasphere formation. These effects are consistent with the androgen-independent self-renewal of cells with stem cell characteristics and the androgen-dependent proliferation of transit amplifying cells. As the canonical WNT signaling effector $\beta$-catenin can also associate with the androgen receptor, we propose a model for tumour propagation involving a balance between WNT and androgen receptor activity. That would affect the self-renewal of a cancer cell with stem cell characteristics and drive transit amplifying cell proliferation and differentiation. In conclusion, we provide evidence that WNT activity regulates the selfrenewal of prostate cancer cells with stem cell characteristics independently of androgen receptor activity. Inhibition of WNT signaling therefore has the potential to reduce the self-renewal of prostate cancer cells with stem cell characteristics and improve the therapeutic outcome.

Keywords: prostate cancer, stem cell, WNT, androgen receptor, LNCaP, prostasphere

Cell Research (2009) 19:683-697. doi: 10.1038/cr.2009.43; published online 14 April 2009

\section{Introduction}

Prostate cancer is a leading cause of male cancerrelated deaths [1]. In those who are not suitable for attempts at cure with radiotherapy or surgery, treatment is by androgen deprivation therapy, which effectively shrinks androgen-dependent tumours. However, this usually leads to recurrent androgen-independent prostate cancer, which undergoes metastasis $[2,3]$ with a median survival time of 20-24 months [4]. The majority of human prostate adenocarcinoma cells express luminal cell markers that include androgen receptor (AR), prostate-

Correspondence: David M Prowse

Tel: +44 0207014 0421; Fax: +44 02070140431

E-mail: d.m.prowse@qmul.ac.uk

Received 15 September 2008; revised 3 December 2008; accepted 7 January 2009; published online 14 April 2009 specific antigen (PSA), keratins 8 and 18 [5]. This has led to the speculation that prostate cancers are derived from either mature luminal cells that have acquired proliferation ability, transit-amplifying epithelial cells that precede luminal cell differentiation or from androgenindependent prostate stem cells $[6,7]$. A role for stem cells is suggested by the regenerative capacity of rodent prostate glands following androgen ablation [8], the ability of some prostate cancer cells to survive androgen deprivation therapy and to subsequently progress to metastatic androgen-independent prostate cancer $[5,6]$, and the finding that AR-negative human prostate cancer cells with stem cell characteristics can give rise to AR-positive cells $[9,10]$.

Cancer cells that are capable of self-renewal and differentiation, properties of normal tissue stem cells, have been shown to be the fundamental cause of both human acute myeloid and lymphoid leukemia [11, 12]. These 
cells have been termed "cancer stem cells" and there is increasing evidence that cells with stem cell characteristics are also the driving force behind tumour formation in many solid tissue cancers including cancers of brain, colon and breast [13-15]. Non-adherent, defined media culture techniques have been used to isolate neuronal, colon and breast cancer cells with stem cell characteristics [1518]. The use of this culture system has recently been extended to cells derived from the prostate and it has been reported that hTERT-immortalized primary prostate cancer cells can form spheres which were termed "prostaspheres" [19] and that dissociated primary murine prostate stem cells demonstrate clonal self-renewal in prostate sphere cultures [20]. In this study we report the use of non-adherent sphere cultures for clonal growth of single cells from human prostate cancer cell lines.

As the majority of androgen-independent cancer cells express the AR [21], the aberrant activation of AR by low circulating levels of androgen may contribute to the growth of androgen-independent prostate cancers [5]. Several proteins have been described, which could potentiate AR transactivity and contribute to androgenindependent prostate cancer [5]. One such protein is $\beta$-catenin [22], the major effector of canonical WNT signaling [23]. WNT signaling can be inhibited by Dickkopf-1 (DKK1), which directly binds to the cell surface protein LRP5/6 (associated with the Frizzled family of WNT receptors) and blocks canonical WNT signaling [24-26], or by Soluble Frizzled Related Proteins (sFRP), which resemble the cysteine-rich ligand-binding domain of the Frizzled family and are believed to function as extracellular WNT inhibitors [27, 28]. Mutations that stabilize $\beta$-catenin occur in a variety of human tumours and can lead to accumulation of nuclear $\beta$-catenin [23]. In prostate cancer activation of $\beta$-catenin by mutation is reported in $5 \%$ of tumours $[29,30]$. However, WNT signaling may also play a significant role in the development and progression of metastatic androgenindependent prostate cancer, as $25-38 \%$ of these cancers have tumour cells with nuclear $\beta$-catenin localization [29, $30]$. Increased nuclear $\beta$-catenin accumulation in prostate cancer cells could cause transcriptional changes through its interaction with TCF family transcription factors or the AR. In this study, we show that WNT signaling can regulate the self-renewal of prostate cancer cells with stem cell characteristics independently of AR activity.

\section{Results}

A stem cell-like subpopulation exists within prostate cell lines

Utilizing the technique of non-adherent suspension culture or sphere formation (Figure 1A) we have identified a subpopulation of cells with prostasphere-forming ability within the prostate cancer cell lines 22RV1, DU145, PC3, VCaP, LNCaP and the LNCaP subline C42B. Whereas the majority of cells in suspension culture failed to proliferate, rare cells $(0.1-8 \%)$ displayed the ability to grow as spherical prostaspheres (Figure 1B). The efficiency of prostasphere formation $(\mathrm{P} 0)$ varied and was highest in the cell types of $\mathrm{LNCaP}$ and its androgenindependent derivative $\mathrm{C} 4-2 \mathrm{~B}$, which express $\mathrm{AR}$ and PSA [31].

\section{Self-renewal and proliferation of prostaspheres}

To confirm that the $\mathrm{LNCaP}$ and $\mathrm{C} 4-2 \mathrm{~B}$ prostasheres were the progeny of individual cells, rather than the aggregation of quiescent cells, we performed clonal growth assays with single cells derived from P0 prostaspheres (Figure 1C). Following P0 prostasphere dissociation and plating at one cell per well, we observed the generation of one to three new spheres (P1-P2) from single cells (Figure 1D). These prostaspheres were typically 25-100 $\mu \mathrm{m}$ in diameter after 6 days. At 12 days only $20 \%$ of LN$\mathrm{CaP}$ prostaspheres were greater than $100 \mu \mathrm{m}$ in diameter, compared with $60 \%$ of $\mathrm{C} 4-2 \mathrm{~B}$ prostaspheres. The 12 day LNCaP spheres were the same size as $\mathrm{C} 4-2 \mathrm{~B}$ spheres cultured for 6 days (Figure 1E). It was also possible to generate further new spheres from single dissociated cells of P1-2 prostaspheres. This clonal protasphere selfrenewal was observed for four passages with $\mathrm{LNCaP}$ cells and eight passages with $\mathrm{C} 4-2 \mathrm{~B}$ cells (Figure 1D). To estimate the number of cells contained in an individual prostate sphere and the total number of cells that could be derived from a single $\mathrm{P} 0$ cell, we used the method described by Reynolds and Rietze [32]. C4-2B-derived spheres after 12 days in culture had a median diameter of $100 \mu \mathrm{m}$ and an average of 1000 cloned cells. As the cells derived from spheres have been diluted to only one cell per well (Figure 1C) at each passage this suggests that a self-renewing $\mathrm{C} 4-2 \mathrm{~B}$ P0 cell has the capacity to generate, after eight passages, 128000 daughter cells in 128 spheres, (based on our observation that each sphere on average gave rise to two daughter spheres and would contain 1000 cells $/ 100 \mu \mathrm{m}$ sphere). As the number of LNCaP spheres reduced with serial passage and the LN$\mathrm{CaP}$ spheres had a reduced median size, this suggests the self-renewing LNCaP P0 cell had the capacity to generate 2250 daughter cells in five spheres (containing 450 cells/75 $\mu \mathrm{m}$ sphere).

\section{Prostasphere characterization}

Keratin 5/14 expression was not detected in adherent cultures, rarely detected in $\mathrm{LNCaP}$ spheres and signifi- 
A
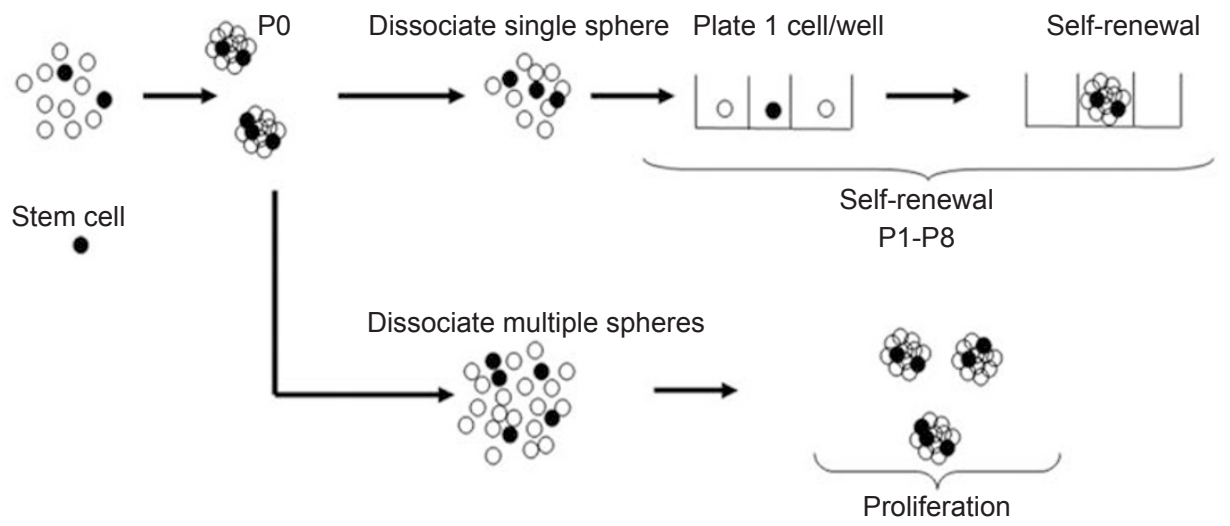

B
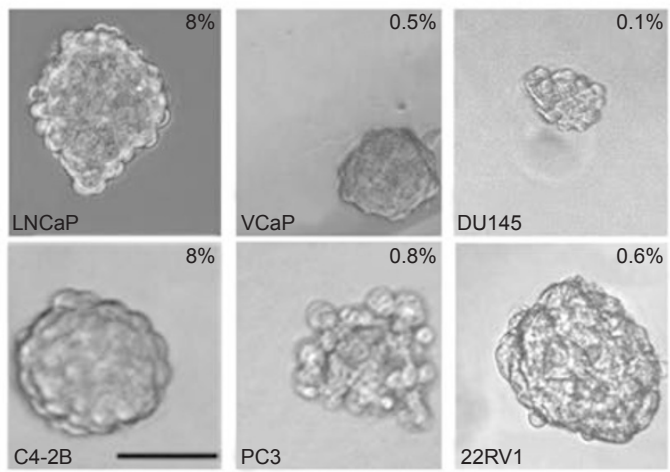

PC3

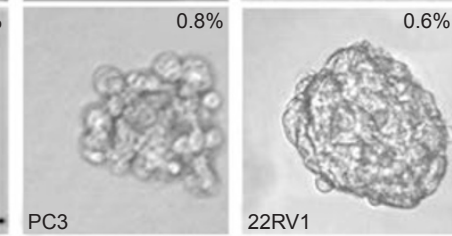

D

C Day 0
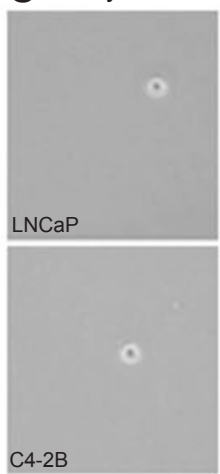

C4-2B
Day 6

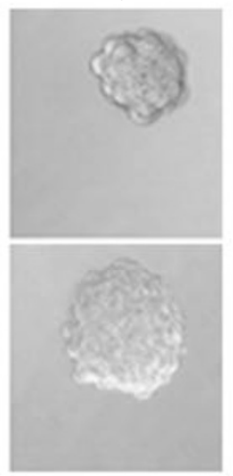

Day 12

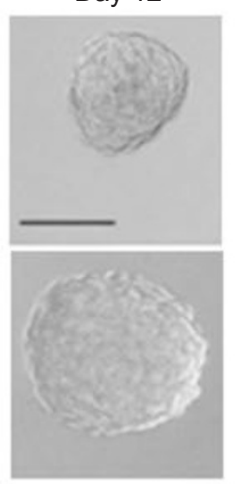

E
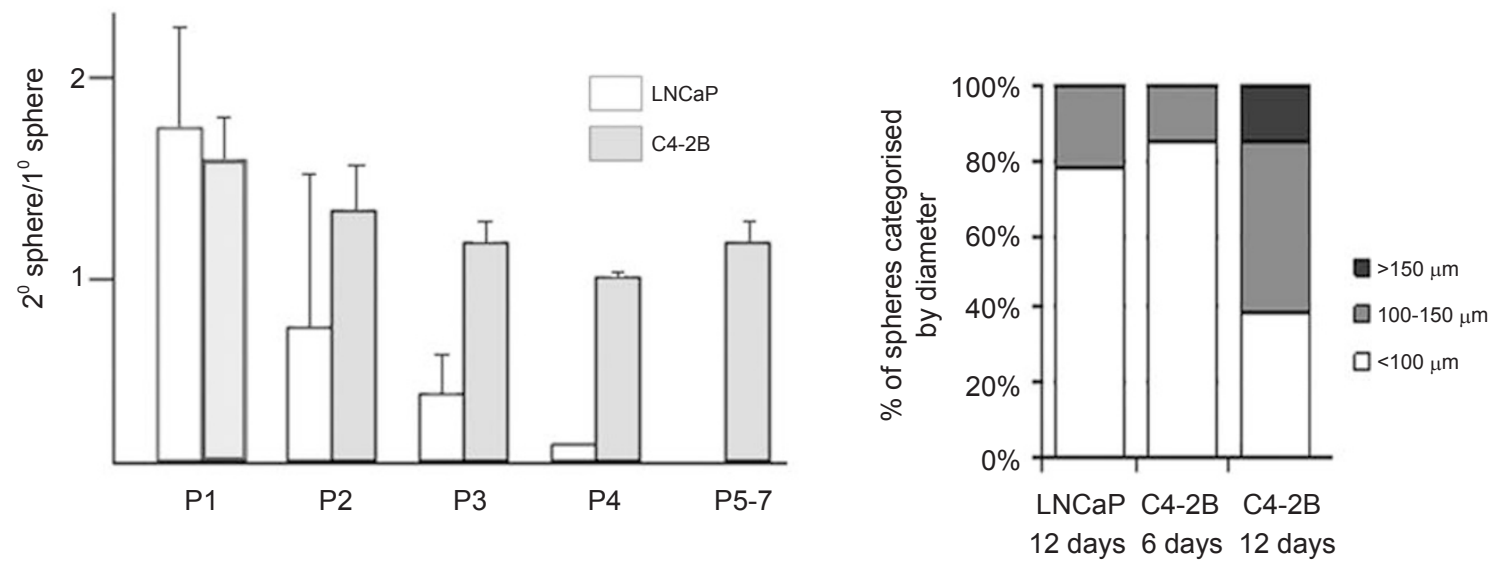

Figure 1 Prostasphere formation and culture. (A) Schematic representation of prostate cancer cell prostasphere self-renewal and proliferation. Adherent prostate cancer cells were dissociated and plated at low density in non-adherent cultures to form P0 spheres. Individual spheres were isolated, dissociated and serial dilution used to replate cells at 1 cell/well. After 6-10 days the new $\mathrm{P} 1$ spheres were counted, dissociated and a single cell/well replated $\left(\mathrm{P} 2^{+}\right)$, to demonstrate the ability of single cells to self-renewal. Dissociated spheres obtained in P0 were also serially plated in order to proliferate the spheres. (B) Prostasphere formation (P0) was observed with different prostate cell lines, with only a small percentage of cells being able to form spheres. (C) Typical LNCaP and C4-2B spheres generated from a single cell after 6 and 12 days in non-adherent culture (scale bar $50 \mu \mathrm{m}$ ). (D) LNCaP and C4-2B spheres formation relative to the initial spheres counted at passage (P) 1 to 7 . (E) Percentage of LNCaP and C4-2B spheres with diameters $<100,100-150$ or $>150 \mu \mathrm{m}$. 

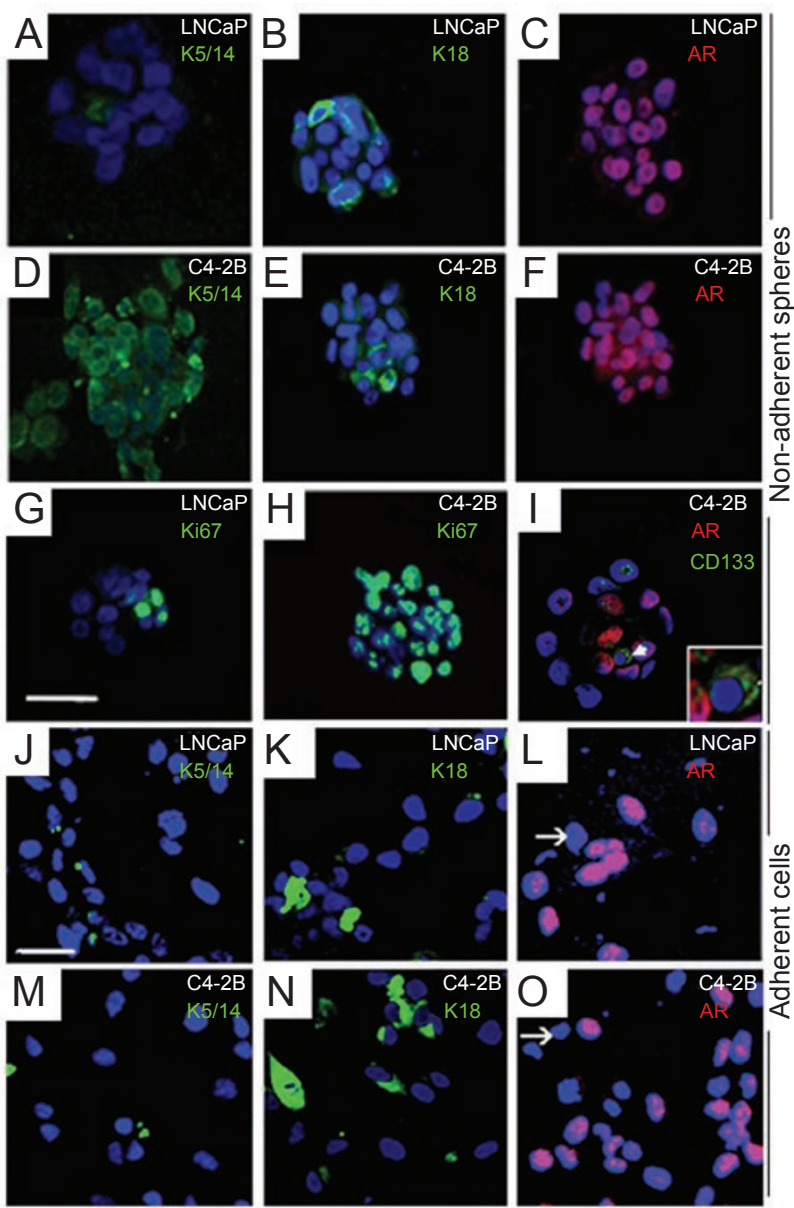

$\mathrm{P}$

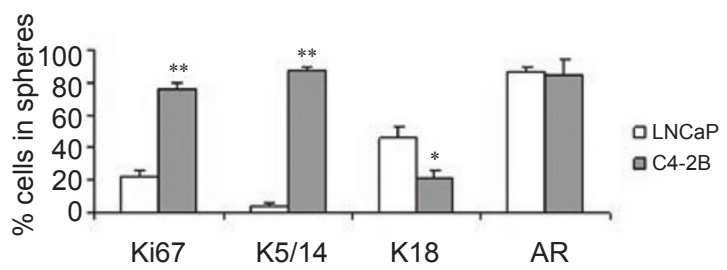

Figure 2 Prostate cancer spheres derived from a single cell contain a heterogeneous population of proliferating and differentiating cells. Expression of proliferation and epithelial differentiation markers in LNCaP (A-C, G) and C4-2B (D-F, H) spheres after 12 and 7 days in culture, respectively. Immunofluorescence showing K5/14 (A, D; green), K18 (B, E; in green), AR (C, F; red) and Ki67 (G, H; green). (I) Co-staining for AR (red) and CD133 (green) in a C4-2B sphere (arrow indicates lack of nuclear AR expression in a CD133 positive cell, enlarged in the inset). Expression of proliferation and differentiation markers in adherent cultures of LNCaP (J-L) and C4-2B (M-O): K5/14 (J, M), K18 (K, N) and AR (L, O), where the arrows indicate ARnegative cells. DAPI nuclear counterstaining (blue), scale bar $50 \mu \mathrm{m}$. (P) Percentage of positive cells for Ki67, K15/14, K18 and AR expression per sphere (Student's $t$-test: $* P=0.05-0.005$; $* * P<0.005)$. cantly expressed in C4-2B spheres $(P<0.0001$; Figure $2)$. In contrast, keratin 18 expression was detected in both adherent cultures (LNCaP 37\%; C4-2B 40\%) and prostaspheres with $\mathrm{LNCaP}$ cells expressing higher levels than $\mathrm{C} 4-2 \mathrm{~B}$ cells $(P<0.014$; Figure 2$)$. Nuclear AR expression was detectable in both $\mathrm{LNCaP}$ and $\mathrm{C} 4-2 \mathrm{~B}$ adherent cultures and prostaspheres, with the majority of both adherent and prostasphere $\mathrm{LNCaP}$ and $\mathrm{C} 4-2 \mathrm{~B}$ cells expressing AR; however negative cells could also be observed (Figure 2). No significant differences were observed between the levels of AR expression in prostasphere cultures (Figure 2). The expression of nuclear Ki67 (indicating cells in the active phases of the cell cycle: G1, S, G2 and mitosis) was significantly higher in the $\mathrm{C} 4-2 \mathrm{~B}$ than the LNCaP spheres $(P<0.0001$; Figure 2). CD133, ABCG2 and CD44 were enriched in both $\mathrm{LNCaP}$ and $\mathrm{C} 4-2 \mathrm{~B}$ prostaspheres compared with adherent cultures (Figure 3). In both $\mathrm{LNCaP}$ and $\mathrm{C} 4-2 \mathrm{~B}$ adherent cultures we were able to identify rare CD133 positive cells $(0.05-0.4 \%$ of the total population) following MACS CD133 enrichment (Figure 3J, inset). CD133 and $\mathrm{ABCG} 2$ expression was detected in $40 \%$ of $\mathrm{LNCaP}$ spheres, whereas $100 \%$ of $\mathrm{C} 4-2 \mathrm{~B}$ spheres were positive for these markers. The number of cells expressing CD133 was significantly higher in C4-2B spheres compared with $\mathrm{LNCaP}$ spheres (Figure $3 \mathrm{M}$ ). C4-2B spheres on average contained $2 \mathrm{CD} 133$ positive cells compared with $0.4 \mathrm{CD} 133$ positive cells per $\mathrm{LNCaP}$ sphere $(P=$ 0.014 ) (Figure 3M). Interestingly, nuclear AR expression was not detected in CD133 positive cells (Figure 2I). The expression of ABCG2 was also significantly higher in $\mathrm{C} 4-2 \mathrm{~B}$ spheres, which on average contained 10 ABCG2 positive cells compared with 1 ABCG2 positive cell per LNCaP sphere $(P<0.0001$; Figure $3 \mathrm{M})$. Similar levels of CD44 expression was detected in both cell types (1-3 positive cells per sphere; $P=0.74$; Figure $3 \mathrm{M}$ ).

\section{Androgen receptor activity affects prostasphere size}

As AR activity could contribute to cell proliferation and sphere self-renewal in both $\mathrm{LNCaP}$ and $\mathrm{C} 4-2 \mathrm{~B}$ cultures, we determined the effects of AR inhibition using the AR antagonist bicalutamide, which inhibits receptor activity in both LNCaP and C4-2B cells. Bicalutamide treatment was associated with a decrease in sphere size in both cell types after 12 days in culture but an increase in the ability of $\mathrm{P} 0$ dissociated cells to generate $\mathrm{P} 1$ spheres (Figure 4A and 4B). Consistent with bicalutamideinhibiting AR activity we observed a significant decrease in the expression by prostasphere cells of the androgenresponsive protein PSA (LNCaP, $P=0.003$; $\mathrm{C} 4-2 \mathrm{~B}, P$ $=0.014)$ and the AR (LNCaP, $P=0.014 ; \mathrm{C} 4-2 \mathrm{~B}, P=$ 0.002; Figure $4 \mathrm{C})$. A reduction in the expression of Ki67 

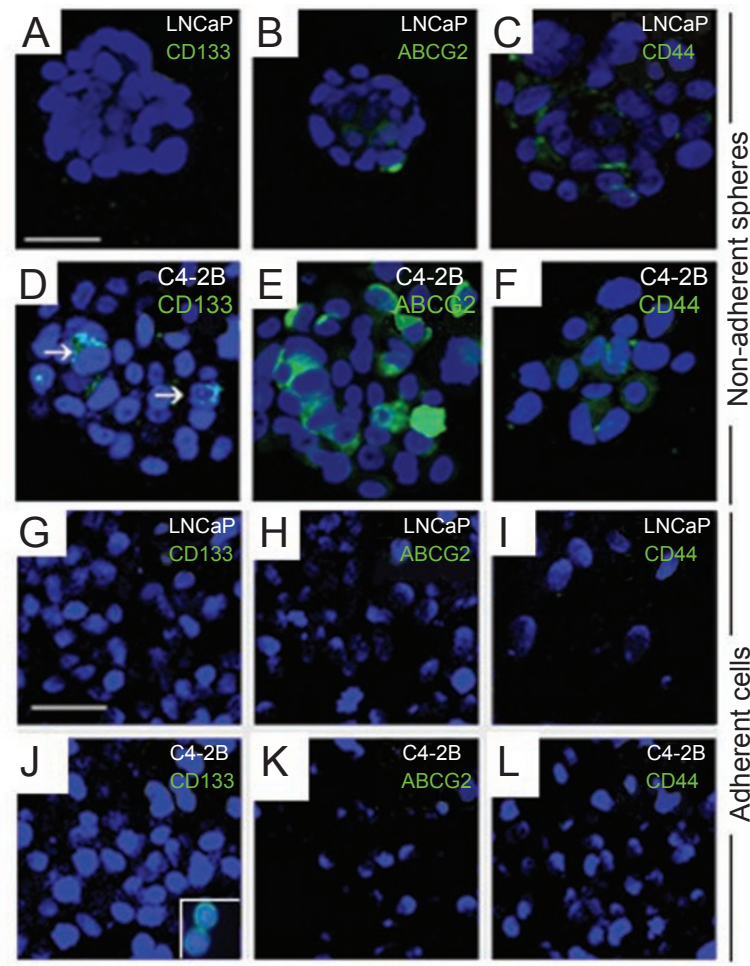

M

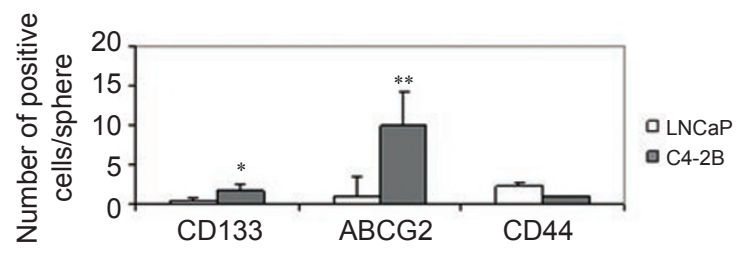

Figure 3 Prostate cancer sphere cells express putative stem cell markers. LNCaP (A-C) and C4-2B (D-F) spheres after 12 and 7 days in culture, stained for $\operatorname{CD} 133$ (A, D), ABCG2 (B, E) and CD44 (C, F) immunofluorescence (green), DAPI nuclear counterstaining (blue), scale bar $50 \mu \mathrm{m}$. Note the CD133 positive cells are indicated by the white arrows. Expression of CD133 (G, J), ABCG2 (H, K), CD44 (I, L) in LNCaP (G-I) and C4-2B (J-L) in adherent culture, scale bar $50 \mu \mathrm{m}$. CD133 immunoreactivity in $\mathrm{C} 4-2 \mathrm{~B}$ cells cultured under adherent conditions following dissociation and MACS CD133 enrichment ( $\mathbf{J}$, inset). (M) Number of CD133, ABCG2 and CD44 positive cells counted per LNCaP and C4-2B spheres (Student's $t$-test: $* P=0.05-0.005$; $* * P<0.005)$.

following bicalutamide treatment was only observed in C4-2B cells $(P=0.001$; Figure $4 C)$, whereas, CD133 expression was not significantly affected in either cell type by bicalutamide treatment (Figure 4D).

WNT signaling regulates prostasphere formation and self-renewal

As WNT dysregulation is associated with a variety of cancers and WNT activity can regulate stem cells in a number of tissues we evaluated the effects of WNT signaling on prostasphere formation. Wnt3a or two secreted inhibitors of WNT signaling were added to dissociated prostate cells derived from $\mathrm{LNCaP}$ or $\mathrm{C} 4-2 \mathrm{~B} \mathrm{P} 0$ spheres (Figure 5). The Wnt3a-treated cells generated larger prostaspheres (Figure 5A-5D, 5G), with two-fold more Wnt3a C4-2B spheres obtaining a diameter of more than $100 \mu \mathrm{m}$. In addition, the ability to form spheres was significantly increased by Wnt3a treatment of dissociated $\mathrm{P} 1$ LNCaP and P1 LNCaP C4-2B cells (Figure 5H). Wnt3atreated $\mathrm{C} 4-2 \mathrm{~B}$ P2 and $\mathrm{P} 3$ spheres also produced a similar 1.5 -fold increase in sphere formation. In contrast, DKK1 and SFRP2 treatment was associated with a decrease in $\mathrm{C} 4-2 \mathrm{~B}$ prostasphere size (no spheres were observed which were $>100 \mu \mathrm{m}$ in diameter) and formation (Figure $5 \mathrm{E}-5 \mathrm{H})$. WNT inhibitor treatment blocked significantly $(P=0.04)$ the self-renewal ability of P0 C4-2B prostaspheres, with $60 \%$ fewer secondary spheres forming in the treated groups. No significant differences in the cell viability or levels of apoptosis within spheres following Wnt3a or DKK1 treatment were observed (Figure 5I5M). Using trypan blue dye exclusion staining, 98.7\% cells were viable in DKK1-treated spheres compared with $100 \%$ in untreated spheres.

\section{Characterization of Wnt3a-treated prostaspheres}

The C4-2B prostaspheres treated with Wnt3a were analysed for the expression of prostate, cell cycle and stem cell-associated markers (Figure 6). Keratin 18 expression was significantly increased in the Wnt3a spheres (C4-2B control 16\% K18 ; C4-2B + Wnt3a $61 \% \mathrm{~K} 18^{+}, P$ $<0.005, n=5$; Figure $6 \mathrm{~A}, 6 \mathrm{D}, 6 \mathrm{M})$. The majority of the cells in the spheres were positive for Ki67 and although the expression of Ki67 was higher in the Wnt3a-treated spheres ( $87 \%$ of cells Ki67 positive) in comparison with untreated cells (74\% of cells Ki67 positive) the difference was not statistically significant $(P=0.066, n=5)$. The majority of cells were AR positive $(87-94 \%)$ and no significant difference in nuclear AR expression was observed following Wnt3a treatment (Figure 6C, 6F, $6 \mathrm{M})$. We then determined expression of CD133, ABCG2 and CD44 in both control and Wnt3a-treated prostaspheres. CD133 and CD44 positive cells were both significantly higher in Wnt3a-treated spheres (Figure 6G, $6 \mathrm{H}, 6 \mathrm{~J}, 6 \mathrm{H}, 6 \mathrm{~K}, 6 \mathrm{~N})$. Control $\mathrm{C} 4-2 \mathrm{~B}$ spheres on average contained two CD133 positive cells whereas in Wnt3atreated spheres five CD133 positive cells were typically detected $(P=0.04, n=8)$. CD44 expression was found in five cells per $\mathrm{C} 4-2 \mathrm{~B}$ sphere whereas 11 positive cells were found on average in a Wnt3a-treated sphere $(P=$ $0.045 n=5)$. Similar levels of ABCG2 expression were 
A

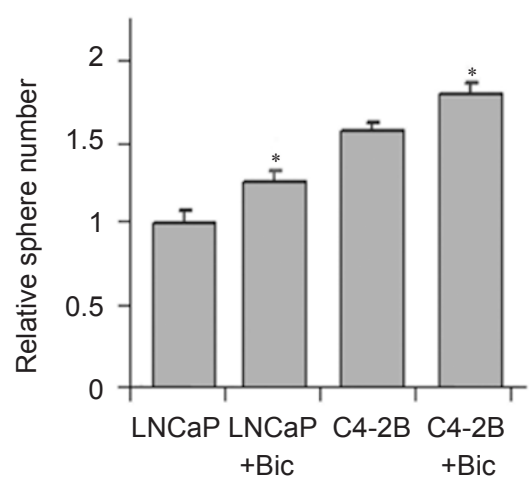

B

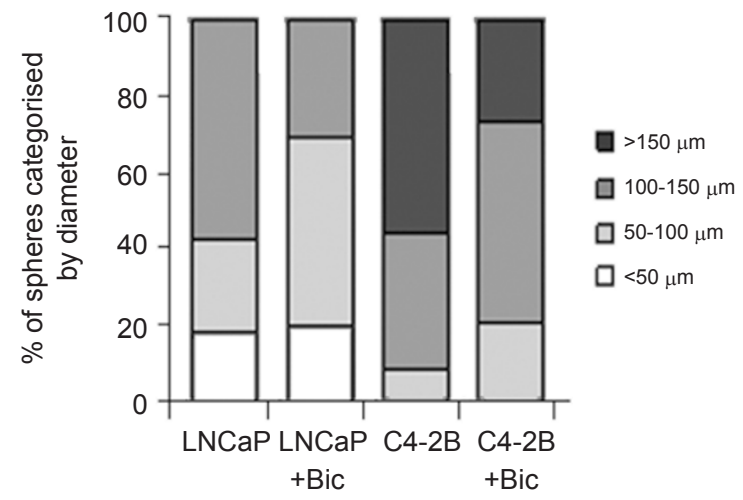

C
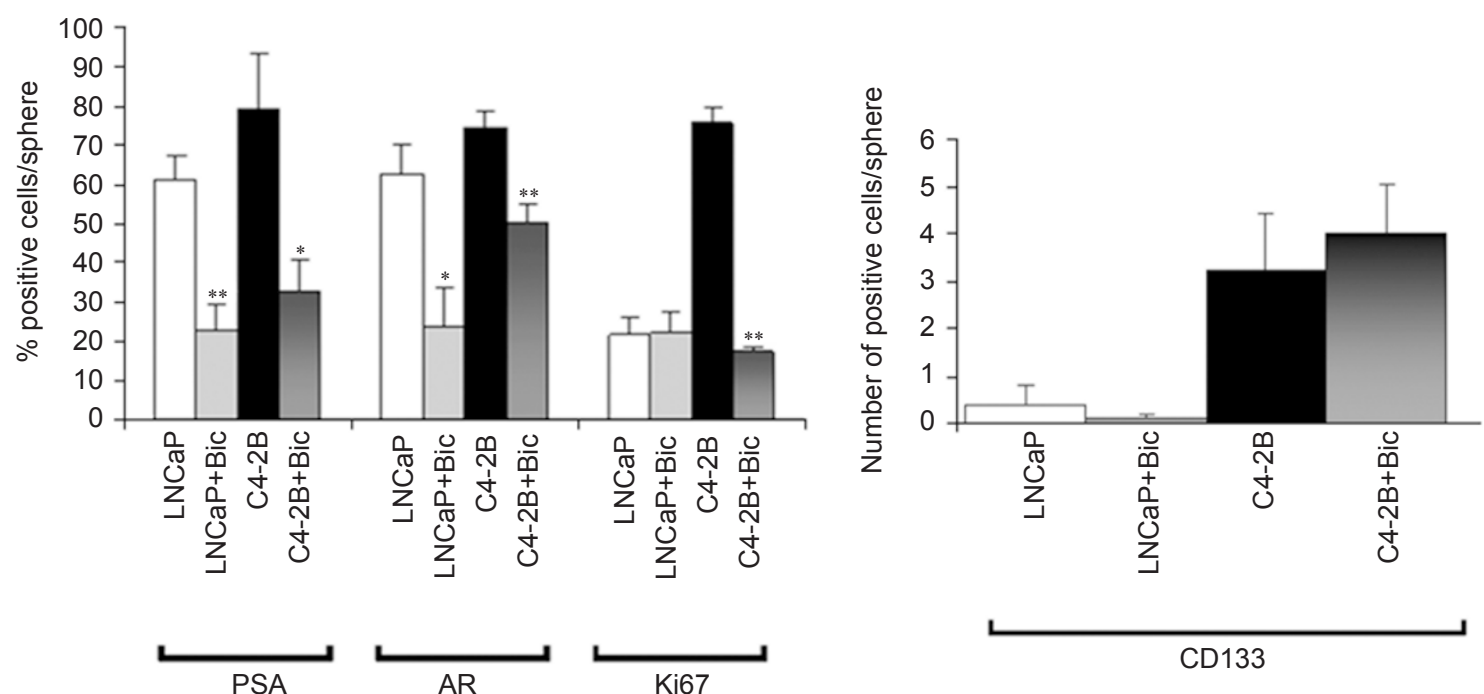

Figure $4 \mathrm{AR}$ activity is not required for sphere formation but affects sphere size. (A) Bicalutamide (Bic) treatment of LNCaP and C4-2B cells increased sphere formation after 12 days in culture. P0 proliferating LNCaP or C4-2B spheres were pooled at day 6 , dissociated and 160 cells plated per well for each culture condition in triplicate. The relative number of spheres that formed after 12 days from 160 cells is shown. (B) Bicalutamide (Bic) treatment caused a reduction in sphere diameter in both LNCaP and C4-2B cells. Percentage of spheres categorized by diameter: $<50,50-100,100-150$ and $>150 \mu \mathrm{m}$, measured after 12 days in culture (Student's $t$-test: $* P=0.05-0.005$ ). (C) Bicalutamide treatment inhibits AR activity affecting PSA, AR expression and Ki67 expression. Percentage of PSA, AR and Ki67 positive cells in control spheres and spheres treated with bicalutamide. (D) Bicalutamide treatment does not affect the number of CD133 positive cells in control spheres and spheres treated with bicalutamide (Student's $t$-test: $* P=0.05-0.005 ; * * P<0.005$ ).

detected in untreated and Wnt3a spheres (10-11 positive cells per sphere; $P=0.73, n=5$ ). Analysis of CD133 and CD44 expression by flow cytometry confirmed the presence of rare $\mathrm{CD} 133 \mathrm{Hi}(1 \%)$ and $\mathrm{CD} 44 \mathrm{Hi}(1.4 \%)$ cells in the prostaspheres. The addition of Wnt3a increased the CD133Hi population 2.2-fold without affecting the CD44Hi (1.5\%) population. Wnt3a-treated prostaspheres were dissociated and sorted for CD133Hi or CD44Hi cells and cultured for 10 days to determine sphere-forming ability. CD44Hi cells failed to form spheres whereas $2-3 \%$ of CD44Lo cells formed spheres. In contrast, $2-3 \%$ of both CD133Hi and CD133Lo selected cells formed spheres. CD44Hi cells therefore have a reduced ability to form spheres while both CD133Hi and CD133Lo cells can form spheres.

Nuclear $\beta$-catenin expression was also affected by 

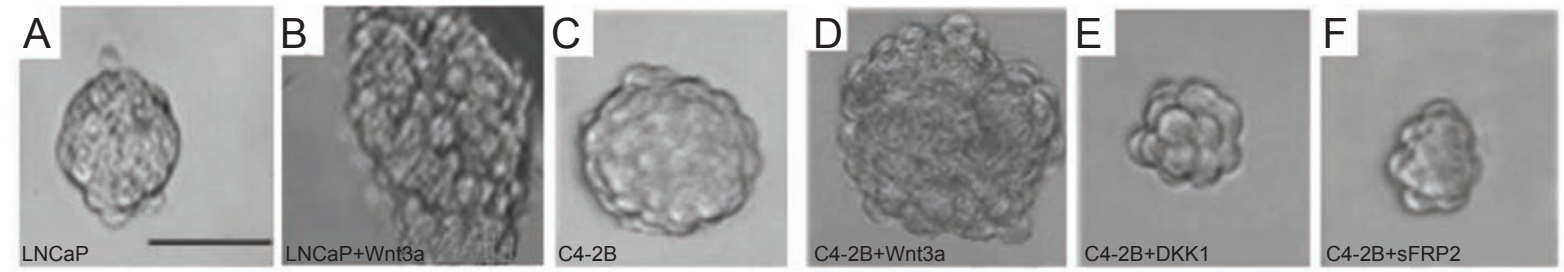

$\mathrm{H}$
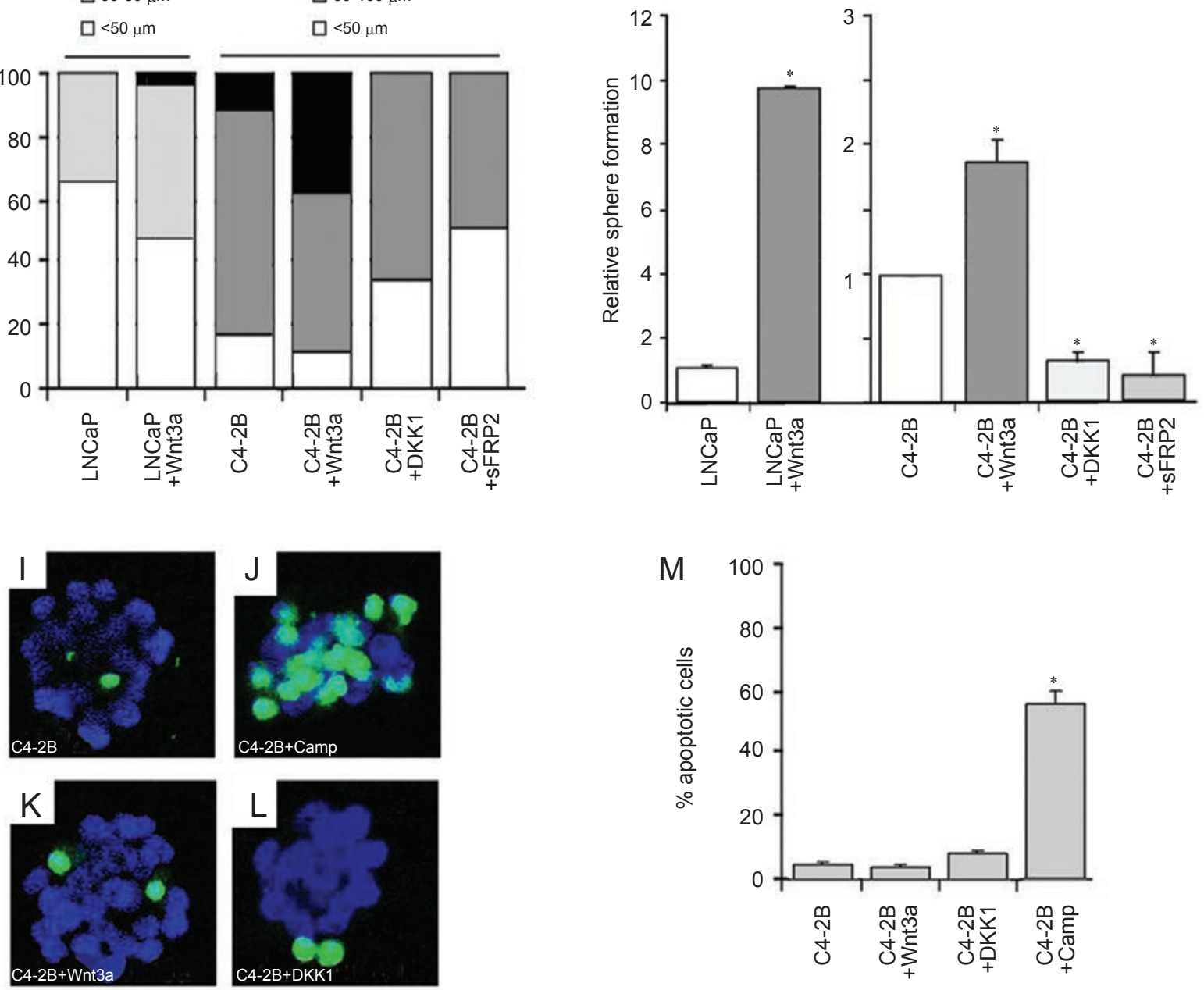

Tunel: C4-2B spheres

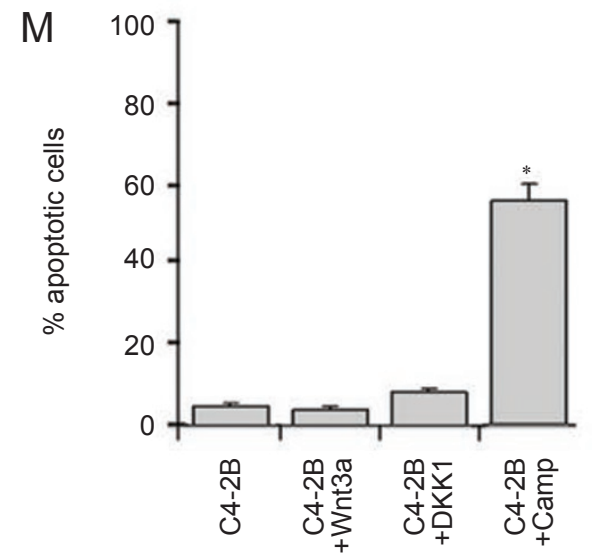

Figure 5 WNT activity regulates prostasphere formation. Representative LNCaP (A, B) and C4-2B (C, D) spheres generated from single cells after 12 days in non-adherent culture. Control cultures (A, C), Wnt3a (B, D), DKK1 (E) and sFRP2 (F). Scale bar $50 \mu \mathrm{m}$. (G) Prostasphere size is increased by Wnt3a treatment and reduced by WNT inhibitors. (H) Prostasphere formation is increased by Wnt3a treatment and reduced by WNT inhibitors. (I-M) Tunel in situ showing apoptotic cells are rare in control (I) C4-2B prostaspheres (5\%) and not induced by Wnt3a (K) or DKK1 (L), whereas camptothecin treatment (J) induces apoptosis in $57 \%$ of cells $(\mathbf{M})$. The results are the mean and standard deviation from three replicates $\left({ }^{*} P<0.05\right)$.

Wnt3a treatment. $\beta$-catenin was strongly detected in untreated spheres at cell junctions and only rarely found in the nucleus, whereas Wnt3a treatment was associated with increased nuclear $\beta$-catenin accumulation (Figure $6 \mathrm{O}$ and $6 \mathrm{P}$ ). The nuclear (blue channel corresponding to DAPI) and $\beta$-catenin (red channel) pixel intensity was 

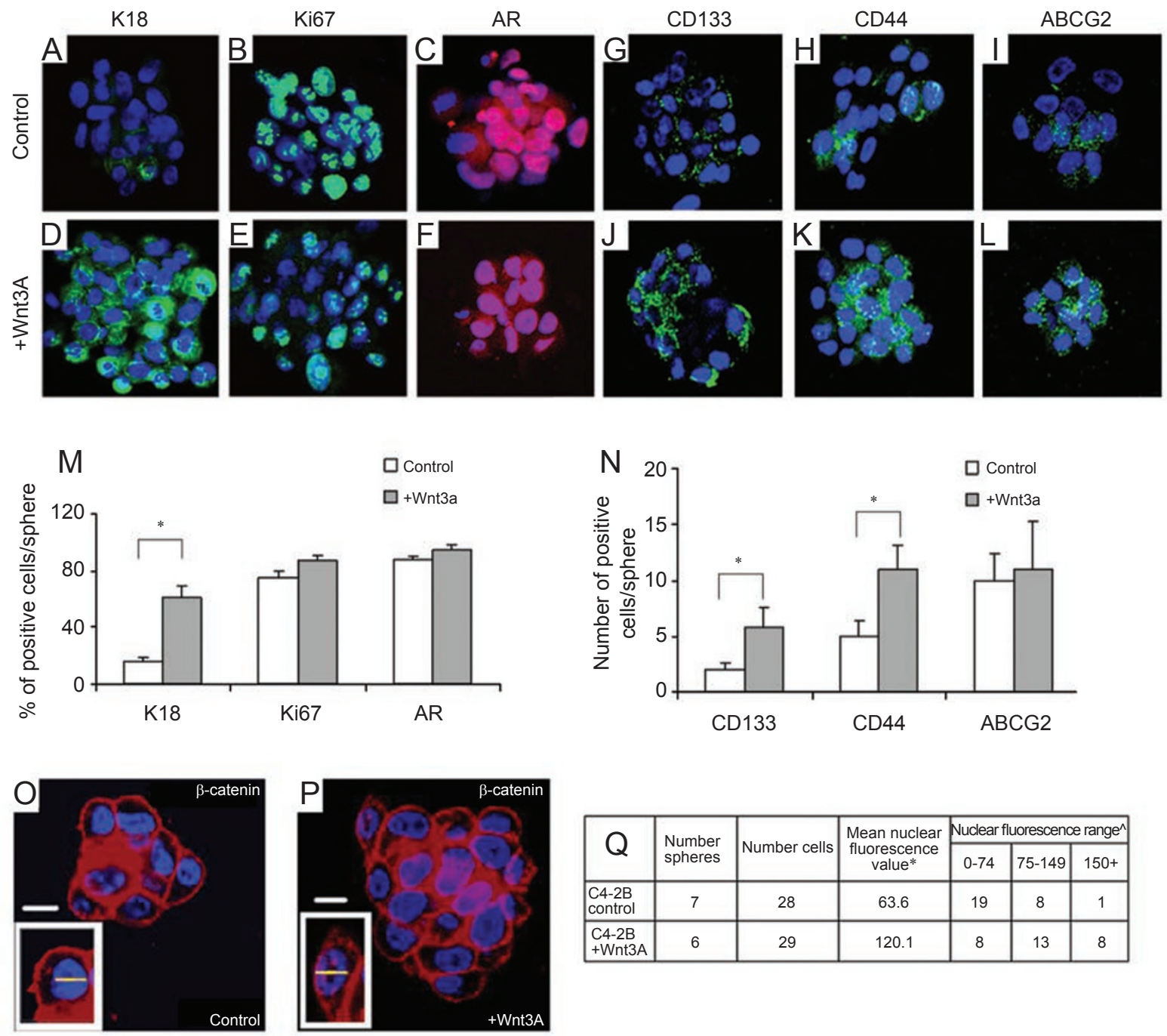

\begin{tabular}{|c|c|c|c|c|c|c|}
\hline \multirow{2}{*}{$\mathrm{Q}$} & \multirow{2}{*}{$\begin{array}{l}\text { Number } \\
\text { spheres }\end{array}$} & \multirow{2}{*}{ Number cells } & \multirow{2}{*}{$\begin{array}{l}\text { Mean nuclear } \\
\text { fluorescence } \\
\text { value** }\end{array}$} & \multicolumn{3}{|c|}{ Nuclear fluorescence range' } \\
\hline & & & & $0-74$ & $75-149$ & $150+$ \\
\hline \begin{tabular}{|l|}
$\mathrm{C} 4-2 \mathrm{~B}$ \\
control \\
\end{tabular} & 7 & 28 & 63.6 & 19 & 8 & 1 \\
\hline \begin{tabular}{|l|l} 
C4-2B \\
+ Wnt3A \\
\end{tabular} & o & 29 & 120 & 8 & 13 & 8 \\
\hline
\end{tabular}

R

S
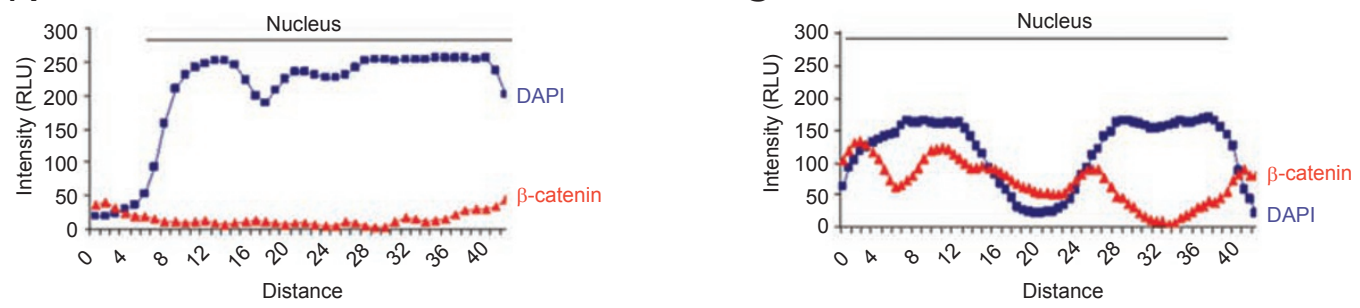

Figure 6 Wnt3a affects keratin 18, CD133, CD44 and nuclear localization of $\beta$-catenin. (A-N) Expression of markers in C42B control (A-C, G-I) and Wnt3a (D-F, J-L) treated spheres after 7 days in culture. Immunofluorescence showing K18 (A, D; green), Ki67 (B, E; green), AR (C, F; red), DAPI nuclear counterstaining (blue), scale bar $50 \mu \mathrm{m}$. (M) Percentage of positive cells for K18, Ki67 and AR expression per sphere. The results are the mean and standard deviation of four replicates (* $P$ < 0.05). Immunofluorescence showing CD133 (G, J; green), CD44 (H, K; green) and ABCG2 (I, L; green) by immunofluorescence, DAPI nuclear counterstaining (blue), scale bar $50 \mu \mathrm{m}$. (N) Number of positive cells for CD133, CD44 and ABCG2 counted per sphere. The results are the mean and standard deviation of five (CD44, ABCG2) and eight (CD133) replicates $\left({ }^{*} P<0.05\right)$. (O, $\left.\mathbf{P}\right)$ Confocal microscope images of $\beta$-catenin expression (Red) in control $(\mathbf{O})$ and Wnt3a $(\mathbf{P})$ treated spheres cultured for 7 days (white scale bar $10 \mu \mathrm{m}$ ). The nucleus was stained by DAPI (blue). Nuclear $\beta$-catenin expression (red/pink) increased following Wnt3a treatment $(\mathbf{O}-\mathbf{Q})$. The pixel intensities in each channels were quantified on the nucleus predefined confocal Z sections (yellow bar inserts). Typical numeral values of pixel intensities are shown plotted on the histogram for $\beta$-catenin (red) and DAPI (blue) for a cell from (R) control and (S) Wnt3a-treated spheres. A significant increase in mean fluorescence nuclear $\beta$-catenin ( $t$-test: $* P<0.0001$ ) and number of cells expressing moderate-high levels nuclear $\beta$-catenin (chisquared: $\left.{ }^{\wedge} P<0.005\right)$ were observed following Wnt3a treatment. 
quantified on a defined nuclear section (Figure 6R and $6 \mathrm{~S})$ [33]. The mean nuclear $\beta$-catenin fluorescence value was significantly higher in Wnt3a-treated cells (fluorescence value of 120) compared with control cells (fluorescence value of $64 ; P<0.0001$ ), with significantly more Wnt3a-treated cells expressed high levels of nuclear $\beta$-catenin (28\%) compared with control cells $(4 \% ; P<$ 0.005) (Figure 6Q).

The WNT effects are independent of androgen receptor activity

We next investigated the interaction between WNT and AR signaling. We treated dissociated $\mathrm{C} 4-2 \mathrm{~B}$ cells for 6 days with Wnt3a (C4-2B + Wnt3a), bicalutamide (C4$2 \mathrm{~B}+\mathrm{Bic})$ and bicalutamide plus Wnt3a $(\mathrm{C} 4-2 \mathrm{~B}+\mathrm{Bic}+$ Wnt3a). Wnt3a treatment on its own caused an increase in sphere size, whereas bicalutmanide treatment was associated with a decrease in sphere size, as expected. The diameter of spheres co-treated with Wnt3a and bicalutamide was similar to the group treated with Wnt3a alone. CD133 expression increased following Wnt3a but not bicalutamide treatment (Figure 7). This Wnt3a-induced increase in CD133 expression was not inhibited by bicalutamide treatment (Figure 7). As expected bicalutamide decreased the number of prostasphere cells expressing the AR (78\% untreated cells, 54\% bicalutamide-treated cells, $P=0.036$; Figure 7). Interestingly, the addition of Wnt3a to bicalutamide-treated cells was associated with a further reduction in AR expression (41\%), demonstrating that Wnt3a does not induce AR expression.

\section{Discussion}

The cancer stem cell hypothesis proposes that tumour cells in vivo are organized as a hierarchy with a cell with stem cell characteristics at the apex, which has the ability to self-renew and generate differentiated progeny (Figure 8) [34]. Normal murine prostate stem cells have been functionally identified by their ability to form prostate spheres [20] and to form differentiated prostate tubular structures when returned to an in vivo environment [20, 35]. The in vivo generation of prostate structures from normal human prostate cells in xenograft studies and the ability to isolate a human basal prostate cell population with enriched capacity for prolonged clonal expansion and luminal differentiation ability have led to the hypothesis that normal human prostate stem cells are located within the basal layer of the gland [36-39]. Several candidate markers of prostate stem cells have been proposed including $\alpha 2 \beta 1$ integrin, Sca-1, CD44, CD133, CD117 and the ATP-binding cassette transporter ABCG2, which is also associated with the resistance of cancer cells to chemotherapeutic agents $[35,38,40,41]$. However, many of these markers are reported to be expressed in both stem and non-stem cells, including stromal and differentiated cells $[35,42,43]$. Although CD117 has recently been reported to be a marker of murine prostate stem cells and a single $\mathrm{Lin}{ }^{-} \mathrm{CD} 117^{+} \mathrm{CD} 44^{+} \mathrm{CD} 133^{+} \mathrm{Sca}-1^{+}$ murine prostate cell has been shown to generate prostate epithelial tubules when combined with rat stromal cells under the renal capsule [35], whether CD117 also defines a human prostate stem cell has not been demonstrated.
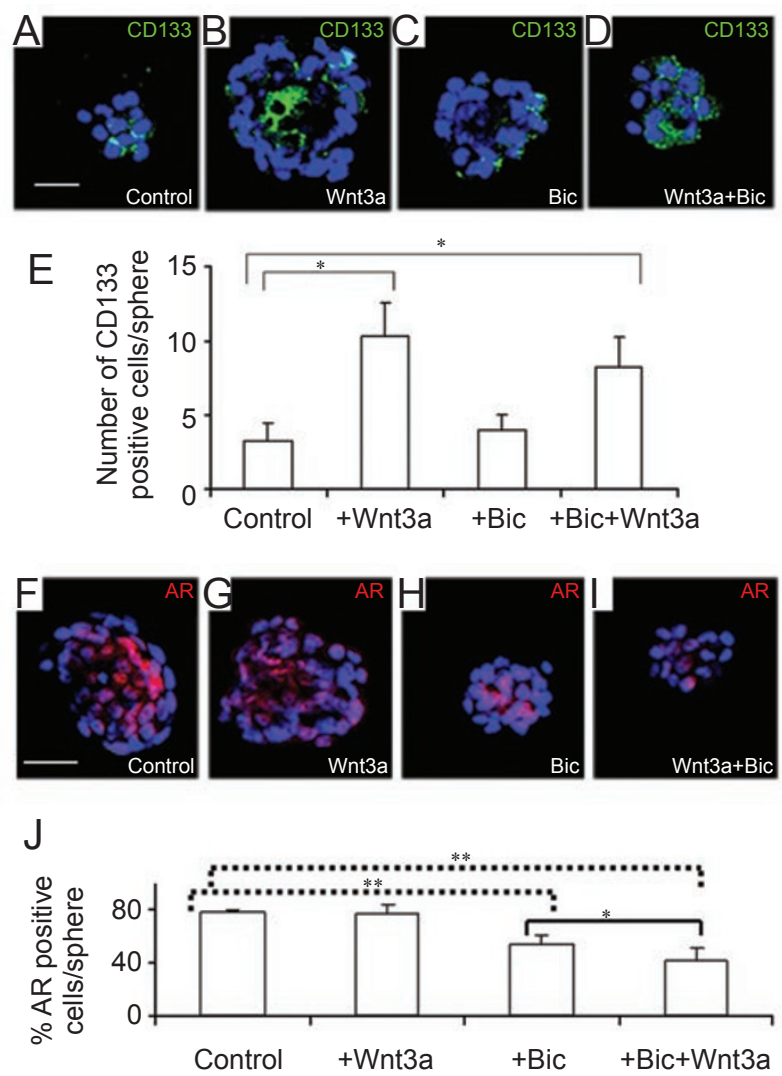

Figure 7 Wnt3a treatment induces CD133 and inhibits AR expression in the presence of bicalutamide. Expression of CD133 in C4-2B spheres: (A) control, (B) Wnt3a, (C) bicalutamide (Bic) and (D) Bic-Wnt3a for 7 days; CD133 (green) and DAPI nuclear counterstaining (blue), scale bar $50 \mu \mathrm{m}$. (E) Number of positive cells counted per sphere in C4-2B control, C4-2B+Wnt3a, C4$2 \mathrm{~B}+\mathrm{Bic}$ and $\mathrm{C} 4-2 \mathrm{~B}+\mathrm{Bic}+\mathrm{Wnt} 3 \mathrm{a}$. The results are the mean and standard deviation of 6-8 spheres per group $\left({ }^{*} P<0.05\right)$. Expression of AR in C4-2B spheres: (F) control, (G) Wnt3a, (I) Bic and (J) Bic+Wnt3a for 7 days; AR (red) and DAPI nuclear counterstaining (blue), scale bar $50 \mu \mathrm{m}$. (J) Percentage of AR positive cells counted per sphere in $C 4-2 B$ control, $C 4-2 B+W n t 3 a$, $\mathrm{C} 4-2 \mathrm{~B}+\mathrm{Bic}$ and $\mathrm{C} 4-2 \mathrm{~B}+\mathrm{Bic}+\mathrm{Wnt} 3 \mathrm{a}$. The results are the mean and standard deviation of $4-8$ spheres per group $(* P=0.05-$ 0.005 ; **P 0.005$)$. 
There is increasing evidence that human prostate cancers are also hierarchal with rare tumour-initiating cells that are distinct from the non-tumour-initiating, bulk population of the tumour [10]. This has led to the proposal that prostate cancer cells with stem cell characteristics may contribute to tumour initiation and progression $[44,45]$. Prostate cancer cells demonstrating clonogenic growth and heterogeneous progeny have been enriched from human prostate tissue by selection with $\alpha 2 \beta 1$ integrin or CD133 [10]. In addition, carcinoma-derived cell lines from prostate (DU145 and PC3) exhibit adherent in vitro colony patterns $[46,47]$, which are similar to the tightly adherent holoclones of primary keratinocytes in adherent clonogenicity assays [48] and are consistent with the retention of self-renewing cells with stem cell characteristics. However, these colony patterns are not generated by LNCaP cells that are only lightly attached to the substrate in adherent cultures, do not become confluent and tend to clump (Bisson and Prowse, unpublished observations). The distinctive PC3 holoclones, but not the paraclones, were also tumourigenic in xenograft assays (showing the presence of self-renewing tumourinitiating cells) and enriched for CD44, $\alpha 2 \beta 1$ integrin and $\beta$-catenin [47]. CD44 is an adhesion molecule with multiple isoforms, which is expressed in both stem and differentiated cell populations and has pleiotropic roles in signaling, migration and homing [34]. Interestingly, CD $44^{\mathrm{HI}}$ LNCaP, LAPC and DU145 cells have also been reported to be enriched in tumour-initiating cells [49, 50]. However, it should also be noted that nine of ten implants of 1000 LAPC9 CD44 $\alpha 2 \beta 1^{+}$cells [49] and two of five implants of 100 DU145 CD44 cells [50] formed xenograft tumours in these studies. The xenograft assay system may also not support the growth of all cancer stem cell populations, as tumour cell engraftment and growth require an intricate network of interactions with diverse supporting murine cells (including fibroblasts, endothelial cells, macrophages, mast cells, and mesenchymal stem cells), and many of the cytokines and receptors required for these two-way interactions are incompatible between mice and humans [51, 52].

Non-adherent sphere cultures have also been used to functionally enrich and identify neural, breast and colon cancer cells with stem cell characteristics. In this study we have investigated the ability of prostate cancer cell lines to form prostaspheres in non-adherent cultures. We found that all the prostate cancer cell lines tested had the ability to form spheres, although heterogeneity existed in the percentage of cells of each cancer line that were able to form spheres, which could reflect differences in the frequency of cells with stem cell characteristics or differences in adaption to non-adherent culture. Interestingly, both AR-negative (PC-3, DU145) and AR-positive (LN$\mathrm{CaP}, \mathrm{VCaP}, 22 \mathrm{RV} 1)$ cell lines were able to form prostaspheres. Primary cells from human prostate cancers were also found to form spheres (Bisson and Prowse, unpublished), which is in agreement with the finding that hTERT-immortalized primary prostate cancer cells form prostaspheres $[19,53]$. Prostasphere formation was most prominent in the androgen-dependent $\mathrm{LNCaP}$ cancer cell line and the androgen-independent LNCaP subline $\mathrm{C} 4-$ $2 \mathrm{~B}$, in which up to $8 \%$ of single cells could form spheres. This is consistent with recent reports that cancer stem cells need not be rare [54].

In addition to their ability to self-renew from a single cell, the analysis of marker expression revealed that the prostaspheres contained a heterogeneous mixture of cells, expressing markers associated with both differentiation (keratin 18 and PSA) and proliferation (Ki67), consistent with prostaspheres originating from a cancer cell with stem cell characteristics. The smaller size and lower potential for self-renewal of LNCaP spheres compared with $\mathrm{C} 4-2 \mathrm{~B}$ spheres, would suggest that LNCaP cells with stem cell characteristics identified using the prostasphere assay, have a greater tendency to differentiate during prolonged culture under these conditions. This is in keeping with the expression in LNCaP prostasphere cells of lower levels of the cell cycle marker Ki67, higher levels of keratin 18 and low levels of keratin 5 (which has been associated with a more aggressive prostate cancer cell phenotype) $[55,56]$. The expression of the stem cell-associated markers, CD133 and CD44, was also significantly enhanced in non-adherent culture and highest in C4-2B prostasphere cells. However, while C4-2B CD133Hi cells formed prostaspheres, CD133 and CD44 selection by FACS failed to enrich for C4-2B cells with prostasphere-forming ability. This may indicate phenotypic heterogeneity between cancer cell populations, as CD133 and CD44 do not always appear to tightly mark a cell population with stem cell characteristics [49, 57], and also reflects the challenge that definitive cancer stem cell markers have not been identified [34, 51].

We also investigated the expression of AR and ABCG2 in the prostasphere cultures, as AR can regulate both the proliferation and differentiation of prostate cells $[3,5]$ and ABCG2 has been reported to identify stem cells [58-61] or a transit amplifying populations $[49,62]$ and is also linked with dihydrotestosterone efflux [63], which could confer reduced sensitivity to androgens. Interestingly, the expression of ABCG2 was significantly higher in $\mathrm{C} 4-2 \mathrm{~B}$ spheres, whereas $\mathrm{AR}$ was expressed by the majority but not all $\mathrm{LNCaP}$ and $\mathrm{C} 4-2 \mathrm{~B}$ prostasphere cells. We therefore determined whether AR activity contributed to cell proliferation and sphere self- 
renewal in both $\mathrm{LNCaP}$ and $\mathrm{C} 4-2 \mathrm{~B}$ cultures, utilizing the AR antagonist bicalutamide, which is widely used to treat patients with hormone naïve prostate cancer and is associated with a reduction in PSA levels [64]. Bicalutamide inhibits the activity and expression of AR in adherent LNCaP cultures [64, 65], causing an AR-specific, progressive inhibition of cell growth and an associated reduction in the percentage of S-phase cells [66]. Bicalutamide also inhibits the proliferation of adherent cultures of C4-2B cells [67]. Bicalutamide treatment reduced the size of both $\mathrm{LNCaP}$ and $\mathrm{C} 4-2 \mathrm{~B}$ prostaspheres but did not inhibit prostasphere formation. The bicalutamide-treated spheres were associated with a significant decrease in both AR and PSA expression, consistent with the expected effects of bicalutamide treatment $[64,68]$. No inhibition of CD133 levels were observed, suggesting AR activity does not contribute to CD133 expression. A significant reduction in the cell cycle marker, Ki67, following bicalutamide treatment was only observed in C4$2 \mathrm{~B}$ prostaspheres. This may be due to the presence of a larger population of $\mathrm{C} 4-2 \mathrm{~B}$ transit amplifying cells that are dependent on AR activity for proliferation. The inhibition of AR activity also caused a small but significant increase in the relative sphere number in both cell types, which is consistent with prostasphere formation being driven by a small population of cells that can self-renew independently of AR activity.

WNT signaling has also been implicated in the regulation of stem cells in a number of tissues and its dysregulation is associated with a variety of cancers [23]. Overexpression of WNT growth factors [25, 69] and reduced expression of WNT inhibitors $[25,70]$ are reported in prostate cancer and WNT growth factors can also regulate adherent human prostate cancer cell growth $[71,72]$. We investigated whether WNT signaling affects prostasphere formation using the small molecule inhibitors DKK1 (which blocks the canonical WNT pathway) and sFRP2 (which blocks both canonical and non-canonical WNT signaling) [28]. We have found that WNT pathway inhibition causes a significant decrease in prostasphere size and relative sphere formation independently of apoptosis. As predicted by the inhibitor studies, treatment with the ligand Wnt3a, which is not expressed by $\mathrm{C} 4-2 \mathrm{~B}$ prostate cancer cells and is an activator of canonical WNT signaling [25, 71], caused a significant increase in prostasphere size and self-renewal. This was associated with a significant increase in the expression of nuclear $\beta$-catenin, consistent with the ability of Wnt3a to activate canonical WNT signaling. This suggests that WNT treatment promotes the self-renewal of prostate cancer cells with stem cell characteristics, consistent with other reports that Wnt3a signaling can preserve an undif- ferentiated phenotype in CD133+ human cord bloodderived cells [73], Wnt3a supports embryonic stem cell self-renewal [74], WNT/ $\beta$-catenin selectively enhanced mammosphere-forming ability of Sca1+ murine mammary cells [75], and the detection of high levels of $\beta$-catenin in PC3 holoclones. We also found that WNT treatment was associated with increased CD133 expression, which may be a direct effect as TCF/LEF1 binding sites are reported in the CD133 promoter [76]. However, although the CD133 positive cells were often AR-negative, CD133 selection failed to enrich for prostasphere-forming ability. The function of CD133 in LNCaP and C4-2B cells is therefore uncertain, although it has been suggested that CD133 functions as an organizer of plasma membrane topology [77]. Interestingly, Wnt3a treatment also caused increased expression of the differentiation-associated keratin 18. This is consistent with WNT signaling being able to promote not only stem cell renewal but also terminal differentiation in the gut crypt and hair follicle lineage $[23,78]$. An association of WNT signaling with differentiation may therefore be a normal mechanism to promote homeostasis, by balancing self-renewal and proliferation with the induction of differentiation, thus preventing uncontrolled cell expansion [23].

The effect of AR inhibition suggests the self-renewal of cells with stem cell characteristics is an androgenindependent event and AR activity may cause these cells to become androgen-dependent transit amplifying cells. WNT signaling can also be affected by AR expression, as

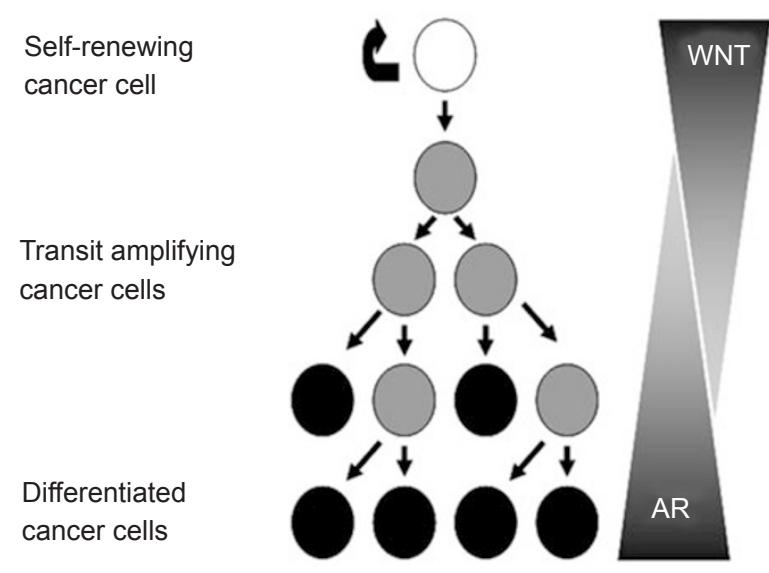

Figure 8 A schematic model of self-renewing cancer cells and their progeny. WNT signaling regulates the self-renewal of cells with stem cell characteristics and the proliferation/differentiation of transit amplifying cells, while AR activity drives the proliferation/differentiation of transit amplifying cells. Interaction between the pathways is also possible as $\beta$-catenin (an effector of WNT signaling) can interact with the AR. 
$\beta$-catenin can directly interact with the TCF transcription factors or the AR [72]. This suggests a model for tumour propagation involving a cellular hierarchy in which the balance between WNT and AR activity regulates both the self-renewal of cancer cells with stem cell characteristics and the proliferation/differentiation of transit amplifying cells (Figure 8).

In conclusion, we provide evidence that WNT activity regulates the self-renewal of prostate cancer cells with stem cell characteristics independently of AR activity. This is consistent with the initial response of prostate cancers to hormone therapy and the subsequent progression to androgen-independent prostate cancer $[3,79]$. In addition, WNT activity may not only maintain prostate cancer but it may also promote metastasis, by contributing to the mechanism through which prostate cancer cells with stem cell characteristics induce osteoblastic activity in the bone [25]. Inhibition of WNT signaling therefore has the potential to reduce the uncontrolled prostate cancer cell self-renewal that drives cancer and improve the therapeutic outcome.

\section{Materials and Methods}

\section{Cell culture and prostasphere formation}

Prostate cancer cell lines PC3, VCAP, LNCaP, 22RV1 and DU145 were purchased from the European Collection of Cell Cultures through Sigma-Aldrich). The androgen independent LNCaP subline C4-2B was purchased from Viromed Laboratories. Androgens are essential for the optimal growth of $\mathrm{LNCaP}$ but not $\mathrm{C} 4-2 \mathrm{~B}$ cells. C4-2B cells were originally derived following the growth of LNCaP cells transplanted into castrated athymic mice [80]. C4-2B cells proliferate as fast in the absence as the presence of androgens and over-express AR [3]. Both LNCaP and C4-2B cells express a common gain-of-function $\mathrm{AR}$ mutant (that remains sensitive to the drug, bicalutamide) [31]. All cells were cultured at $37{ }^{\circ} \mathrm{C}$ in RPMI media without phenol red (Sigma-Aldrich) supplemented with $10 \%(\mathrm{v} / \mathrm{v})$ fetal bovine serum (Invitrogen) or 10\% (v/v) charcoalstripped FBS (Hyclone), $2.4 \mathrm{mM}$ glutamine (Sigma-Aldrich), 1\% (v/v) pyruvate (Sigma-Aldrich), penicillin and streptomycin (50 $\mathrm{U}$ and $50 \mu \mathrm{g} / \mathrm{ml}$ ) (Invitrogen). Cells were detached using trypsin (Sigma-Aldrich), then centrifuged and counted. On low attachment on a 6-well plate (Costar), single cells were plated at 50 cells $/ \mathrm{cm}^{2}$ in DMEM/F12 (Invitrogen ) supplemented with B27 and N2 (Invitrogen). Cells were grown under these conditions for 6-12 days and formed non-adherent $\mathrm{P} 0$ spheres, termed prostaspheres. The prostaspheres were dissociated with Accutase (Sigma-Aldrich) to generate single cells and re-plated into new low attachment plates. For the clonogenicity assay, the prostaspheres were diluted after 6 days in culture and transferred into 96-well low attachment plates (Costar) in order to isolate individual spheres. Each sphere was dissociated with Accutase (Sigma-Aldrich) at $37^{\circ} \mathrm{C}$ and regularly triturated by pipetting to generate single cells $(20 \mathrm{~min})$. By dilution one cell was plated per well of 96 low attachment plates containing DMEM/F12 with B27 and N2. Single cell cloning was confirmed by microscopic analysis.
WNT inhibitors, Wnt $3 a$ and bicalutamide treatement

Prostaspheres were dissociated with accutase (Sigma-Aldrich) to generate single cells and plated at 160 cells/well on a 96-well low attachment plate (Costar). The medium was supplemented with WNT inhibitors DKK1 at $4 \mu \mathrm{g} / \mathrm{ml}$ (R\&D Systems) or sFRP2 at $4 \mu \mathrm{g} / \mathrm{ml}$ (BD Bioscience); Wnt3a at 5, 10 or $20 \mathrm{ng} / \mathrm{ml}$ (R\&D Systems) and the AR inhibitor, bicalutamide, at $1 \mu \mathrm{M}$ (Toronto Research Chemicals Inc) and prostaspheres counted and sized at 7 days. For self-renewal culture assays, individual untreated prostaspheres and those cultured with Wnt3a $(20 \mathrm{ng} / \mathrm{ml})$ and/or bicalutamide $(1 \mu \mathrm{M})$ were serially dissociated with accutase and the cells were re-plated into three wells (low attachment 96-well plates) and cultured for 6 days. Replicate independent experiments were performed.

\section{Tunel and trypan blue assays}

At least 200 spheres were passaged and cultured with and without Wnt3a at $20 \mathrm{ng} / \mathrm{ml}$. The spheres were dissociated using accutase and cells counted using trypan blue (Sigma-Aldrich) to calculate the percentage of live cells. The same number of spheres was used for the in-situ cell death assays (Tunel assay; Roche). Camptothecin (Sigma-Aldrich) treatment at $2.4 \mu \mathrm{M}$, was used as a positive control for apoptosis. The spheres were incubated for 16 hours in chamber slides before staining, following the instruction of the manufacturer. The spheres were analysed by confocal microscopy (Zeiss LSM 510).

\section{Flow cytometry}

The protaspheres after 5-7 days in culture were dissociated with accutase until single cells and labelled with anti-CD133-PE (CD133/1 Myltenyi) or CD44-PE (clone) for $10 \mathrm{~min}$ in dark. The cells were sorted using the FACSAria (BD biosciences). After sorting the cells were seeded in 96-well plates in DMEM/F12 (Invitrogen) supplemented with B27 and N2 (Invitrogen) and Wnt3a at $20 \mathrm{ng} / \mathrm{ml}$.

\section{Immunofluorescence}

The prostaspheres were incubated for $16 \mathrm{~h}$ in chamber slides before paraformaldehyde (4\%) fixation at room temperature for $20 \mathrm{~min}$ [81]. The prostaspheres were washed and incubated with $0.1 \%$ triton $(30 \mathrm{~min})$, and were then washed and blocked with $0.2 \%$ BSA (15 min). Slides were incubated with the following antibodies: anti-AR (dilution 1/50 rabbit IgG polyclonal PG-21, Upstate), ABCG2 (dilution 1/50 rat IgG2a monoclonal BXP-53, Abcam), keratin 18 (dilution $1 / 50$ mouse IgG1 monoclonal DC10, Abcam), CD44 (dilution 1/50 mouse IgG2b monoclonal G44-26, BD Pharmingen), CD133 (dilution 1/100 rabbit polyclonal to CD133, Abcam), Ki67 (dilution 1/50 clone MIB-1, DakoCytomation) and $\beta$-catenin (dilution $1 / 500$ mouse $\operatorname{IgG} 1$ clone $14 / \beta$-catenin, BD Transduction Laboratories). The slides were then washed with PBS and incubated $(1 \mathrm{~h})$ with secondary antibodies labelled with Alexa 488 and 594 (Invitrogen). Control incubations with nonspecific primary antibodies or secondary antibody alone did not label. The slides were finally washed with PBS and mounted using mounting solution containing DAPI before observation using a confocal microscope (Zeiss LSM 510).

\section{Confocal $\beta$-catenin analysis}

Prostaspheres images were analyzed for nuclear $\beta$-catenin 
expression following Wnt3a treatment. Confocal imaging was performed using a Zeiss LSM 510, 40× objective zoom 2-3. Images were analyzed using personal computer-based LSM 510 and ImageJ software. To evaluate the level of $\beta$-catenin expressed in the cell nucleus, we selected distinct prostasphere cells and defined nuclear horizontal sections corresponding to the DAPI nuclear staining (blue). We quantified the intensities of the pixels in each channel (DAPI: blue; $\beta$-catenin: red) on the sections and generated histograms. The levels of nuclear $\beta$-catenin were determined and mean values calculated within the nucleus [33].

\section{Statistical analysis}

Results of prostaspheres formation and sized were analyzed by $t$-test and/or chi-square test using Minitab software. $P<0.05$ was considered significant.

\section{Acknowledgments}

We would like to acknowledge our colleague Ms Beade Numbre for technical assistance with prostate cancer cell line culture and P0 prostasphere establishment. We would like to thank the Bart's and the London Charitable Foundation and the Orchid Cancer Appeal for funding this research. DMP is a Research Council UK Academic Fellow.

\section{References}

1 Carson CC, 3rd. Carcinoma of the prostate: overview of the most common malignancy in men. NC Med J 2006; 67:122127.

2 Shaw GL, Wilson P, Cuzick J, et al. International study into the use of intermittent hormone therapy in the treatment of carcinoma of the prostate: a meta-analysis of 1446 patients. BJU Int 2007; 99:1056-1065.

3 Shaw G, Prowse DM. Inhibition of androgen-independent prostate cancer cell growth is enhanced by combination therapy targeting Hedgehog and ErbB signalling. Cancer Cell Int 2008; 8:3.

4 Petrylak DP, Tangen CM, Hussain MH, et al. Docetaxel and estramustine compared with mitoxantrone and prednisone for advanced refractory prostate cancer. $N$ Engl J Med 2004; 351:1513-1520.

5 Litvinov IV, De Marzo AM, Isaacs JT. Is the Achilles' heel for prostate cancer therapy a gain of function in androgen receptor signaling? J Clin Endocrinol Metab 2003; 88:2972-2982.

6 Lawson DA, Witte ON. Stem cells in prostate cancer initiation and progression. J Clin Invest 2007; 117:2044-2050.

7 Verhagen AP, Ramaekers FC, Aalders TW, et al. Colocalization of basal and luminal cell-type cytokeratins in human prostate cancer. Cancer Res 1992; 52:6182-6187.

8 English HF, Santen RJ, Isaacs JT. Response of glandular versus basal rat ventral prostatic epithelial cells to androgen withdrawal and replacement. Prostate 1987; 11:229-242.

9 Patrawala L, Calhoun T, Schneider-Broussard R, et al. Highly purified CD44+ prostate cancer cells from xenograft human tumors are enriched in tumorigenic and metastatic progenitor cells. Oncogene 2006; 25:1696-1708.

10 Collins AT, Berry PA, Hyde C, et al. Prospective identification of tumorigenic prostate cancer stem cells. Cancer Res 2005; 65:10946-10951.

11 Bonnet D, Dick JE. Human acute myeloid leukemia is organized as a hierarchy that originates from a primitive hematopoietic cell. Nat Med 1997; 3:730-737.

12 George AA, Franklin J, Kerkof K, et al. Detection of leukemic cells in the CD34(+)CD38(-) bone marrow progenitor population in children with acute lymphoblastic leukemia. Blood 2001; 97:3925-3930.

13 Al-Hajj M, Wicha MS, Benito-Hernandez A, et al. Prospective identification of tumorigenic breast cancer cells. Proc Natl Acad Sci USA 2003; 100:3983-3988.

14 Singh SK, Clarke ID, Terasaki M, et al. Identification of a cancer stem cell in human brain tumors. Cancer Res 2003; 63:5821-5828.

15 Ricci-Vitiani L, Lombardi DG, Pilozzi E, et al. Identification and expansion of human colon-cancer-initiating cells. Nature 2007; 445:111-115.

16 Uchida N, Buck DW, He D, et al. Direct isolation of human central nervous system stem cells. Proc Natl Acad Sci USA 2000; 97:14720-14725.

17 Wicha MS, Liu S, Dontu G. Cancer stem cells: an old idea--a paradigm shift. Cancer Res 2006; 66:1883-1890.

18 Dontu G, Abdallah WM, Foley JM, et al. In vitro propagation and transcriptional profiling of human mammary stem/progenitor cells. Genes Dev 2003; 17:1253-1270.

19 Miki J, Furusato B, Li H, et al. Identification of putative stem cell markers, CD133 and CXCR4, in hTERT-immortalized primary nonmalignant and malignant tumor-derived human prostate epithelial cell lines and in prostate cancer specimens. Cancer Res 2007; 67:3153-3161.

20 Xin L, Lukacs RU, Lawson DA, Cheng D, Witte ON. Selfrenewal and multilineage differentiation in vitro from murine prostate stem cells. Stem Cells 2007; 25:2760-2769.

21 Linja MJ, Savinainen KJ, Saramaki OR, et al. Amplification and overexpression of androgen receptor gene in hormonerefractory prostate cancer. Cancer Res 2001; 61:3550-3555.

22 Truica CI, Byers S, Gelmann EP. Beta-catenin affects androgen receptor transcriptional activity and ligand specificity. Cancer Res 2000; 60:4709-4713.

23 Clevers H. Wnt/beta-catenin signaling in development and disease. Cell 2006; 127:469-480.

24 Glinka A, Wu W, Delius H, et al. Dickkopf-1 is a member of a new family of secreted proteins and functions in head induction. Nature 1998; 391:357-362.

25 Hall CL, Bafico A, Dai J, Aaronson SA, Keller ET. Prostate cancer cells promote osteoblastic bone metastases through Wnts. Cancer Res 2005; 65:7554-7560.

26 Mao B, Wu W, Davidson G, et al. Kremen proteins are Dickkopf receptors that regulate $\mathrm{Wnt} /$ beta-catenin signalling. $\mathrm{Na}$ ture 2002; 417:664-667.

27 Hoang B, Moos M, Jr, Vukicevic S, Luyten FP. Primary structure and tissue distribution of FRZB, a novel protein related to Drosophila frizzled, suggest a role in skeletal morphogenesis. J Biol Chem 1996; 271:26131-26137.

28 Hall CL, Keller ET. The role of Wnts in bone metastases. Cancer Metastasis Rev 2006; 25:551-558.

29 Chesire DR, Isaacs WB. Ligand-dependent inhibition of betacatenin/TCF signaling by androgen receptor. Oncogene 2002; 
21:8453-8469.

30 de la Taille A, Rubin MA, Chen MW, et al. Beta-catenin-related anomalies in apoptosis-resistant and hormone-refractory prostate cancer cells. Clin Cancer Res 2003; 9:1801-1807.

31 van Bokhoven A, Varella-Garcia M, Korch C, et al. Molecular characterization of human prostate carcinoma cell lines. Prostate 2003; 57:205-225.

32 Reynolds BA, Rietze RL. Neural stem cells and neurospheres-re-evaluating the relationship. Nat Methods 2005; 2:333-336.

33 Adam L, Mazumdar A, Sharma T, Jones TR, Kumar R. A three-dimensional and temporo-spatial model to study invasiveness of cancer cells by heregulin and prostaglandin E2. Cancer Res 2001; 61:81-87.

34 Visvader JE, Lindeman GJ. Cancer stem cells in solid tumours: accumulating evidence and unresolved questions. Nat Rev 2008; 8:755-768.

35 Leong KG, Wang BE, Johnson L, Gao WQ. Generation of a prostate from a single adult stem cell. Nature 2008; 456:804808.

36 Hudson DL, O'Hare M, Watt FM, Masters JR. Proliferative heterogeneity in the human prostate: evidence for epithelial stem cells. Lab Invest 2000; 80:1243-1250.

37 Hudson DL, Guy AT, Fry P, et al. Epithelial cell differentiation pathways in the human prostate: identification of intermediate phenotypes by keratin expression. $J$ Histochem $C y$ tochem 2001; 49:271-278.

38 Collins AT, Habib FK, Maitland NJ, Neal DE. Identification and isolation of human prostate epithelial stem cells based on alpha(2)beta(1)-integrin expression. J Cell Sci 2001; 114:3865-3872.

39 Litvinov IV, Vander Griend DJ, Xu Y, et al. Low-calcium serum-free defined medium selects for growth of normal prostatic epithelial stem cells. Cancer Res 2006; 66:8598-8607.

40 Huss WJ, Gray DR, Greenberg NM, Mohler JL, Smith GJ. Breast cancer resistance protein-mediated efflux of androgen in putative benign and malignant prostate stem cells. Cancer Res 2005; 65:6640-6650.

41 Richardson GD, Robson CN, Lang SH, et al CD133, a novel marker for human prostatic epithelial stem cells. J Cell Sci 2004; 117:3539-3545

42 Xin L, Lawson DA, Witte ON. The Sca-1 cell surface marker enriches for a prostate-regenerating cell subpopulation that can initiate prostate tumorigenesis. Proc Natl Acad Sci USA. 2005; 102:6942-6947.

43 Shmelkov SV, Butler JM, Hooper AT, et al. CD133 expression is not restricted to stem cells, and both CD133+ and CD133- metastatic colon cancer cells initiate tumors. J Clin Invest 2008; 118:2111-2120.

44 Signoretti S, Loda M. Prostate stem cells: from development to cancer. Semin Cancer Biol 2007; 17:219-224.

45 Collins AT, Maitland NJ. Prostate cancer stem cells. Eur J Cancer 2006; 42:1213-1218.

46 Locke M, Heywood M, Fawell S, Mackenzie IC. Retention of intrinsic stem cell hierarchies in carcinoma-derived cell lines. Cancer Res 2005; 65:8944-8950.

47 Li H, Chen X, Calhoun-Davis T, Claypool K, Tang DG. PC3 human prostate carcinoma cell holoclones contain self-renewing tumor-initiating cells. Cancer Res 2008; 68:1820-1825.

48 Janes SM, Ofstad TA, Campbell DH, Watt FM, Prowse DM.
Transient activation of FOXN1 in keratinocytes induces a transcriptional programme that promotes terminal differentiation: contrasting roles of FOXN1 and Akt. J Cell Sci 2004; 117:4157-4168.

49 Patrawala L, Calhoun-Davis T, Schneider-Broussard R, Tang DG. Hierarchical organization of prostate cancer cells in xenograft tumors: the CD44+alpha2beta1+ cell population is enriched in tumor-initiating cells. Cancer Res 2007; 67:67966805.

50 Hurt EM, Kawasaki BT, Klarmann GJ, Thomas SB, Farrar WL. CD44+ CD24(-) prostate cells are early cancer progenitor/stem cells that provide a model for patients with poor prognosis. Br J Cancer 2008; 98:756-765.

51 Vezzoni L, Parmiani G. Limitations of the cancer stem cell theory. Cytotechnology 2008; 58:3-9.

52 Adams JM, Strasser A. Is tumor growth sustained by rare cancer stem cells or dominant clones? Cancer Res 2008; 68:4018-4021.

$53 \mathrm{Gu}$ G, Yuan J, Wills M, Kasper S. Prostate cancer cells with stem cell characteristics reconstitute the original human tumor in vivo. Cancer Res 2007; 67:4807-4815.

54 Kelly PN, Dakic A, Adams JM, Nutt SL, Strasser A. Tumor growth need not be driven by rare cancer stem cells. Science 2007; 317:337.

55 van Leenders GJ, Aalders TW, Hulsbergen-van de Kaa CA, Ruiter DJ, Schalken JA. Expression of basal cell keratins in human prostate cancer metastases and cell lines. J Pathol 2001; 195:563-570.

56 Schalken JA, van Leenders G. Cellular and molecular biology of the prostate: stem cell biology. Urology 2003; 62:11-20.

57 Beier D, Hau P, Proescholdt M, et al. CD133(+) and CD133(-) glioblastoma-derived cancer stem cells show differential growth characteristics and molecular profiles. Cancer Res 2007; 67:4010-4015.

58 Zhou S, Schuetz JD, Bunting KD, et al. The ABC transporter Bcrp1/ABCG2 is expressed in a wide variety of stem cells and is a molecular determinant of the side-population phenotype. Nat Med 2001; 7:1028-1034.

59 Bunting KD. ABC transporters as phenotypic markers and functional regulators of stem cells. Stem Cells 2002; 20:1120.

60 Pascal LE, Oudes AJ, Petersen TW, et al. Molecular and cellular characterization of ABCG2 in the prostate. BMC Urol 2007; 7:6.

61 Bhatt RI, Brown MD, Hart CA, et al. Novel method for the isolation and characterisation of the putative prostatic stem cell. Cytometry A 2003; 54:89-99.

62 Patrawala L, Calhoun T, Schneider-Broussard R, et al. Side population is enriched in tumorigenic, stem-like cancer cells, whereas ABCG2+ and ABCG2- cancer cells are similarly tumorigenic. Cancer Res 2005; 65:6207-6219.

63 Reya T, Morrison SJ, Clarke MF, Weissman IL. Stem cells, cancer, and cancer stem cells. Nature 2001; 414:105-111.

64 Wang LG, Mencher SK, McCarron JP, Ferrari AC. The biological basis for the use of an anti-androgen and a 5-alpha-reductase inhibitor in the treatment of recurrent prostate cancer: case report and review. Oncol Rep 2004; 11:1325-1329.

65 Waller AS, Sharrard RM, Berthon P, Maitland NJ. Androgen receptor localisation and turnover in human prostate epitheli- 
um treated with the antiandrogen, casodex. J Mol Endocrinol 2000; 24:339-351.

66 Masiello D, Cheng S, Bubley GJ, Lu ML, Balk SP. Bicalutamide functions as an androgen receptor antagonist by assembly of a transcriptionally inactive receptor. J Biol Chem 2002; 277:26321-26326.

67 Lu Y, Zhang J, Dai J, et al. Osteoblasts induce prostate cancer proliferation and PSA expression through interleukin-6-mediated activation of the androgen receptor. Clin Exp Metastasis 2004; 21:399-408.

68 Hara T, Miyazaki J, Araki H, et al. Novel mutations of androgen receptor: a possible mechanism of bicalutamide withdrawal syndrome. Cancer Res 2003; 63:149-153.

69 Hwang SI, Thumar J, Lundgren DH, et al. Direct cancer tissue proteomics: a method to identify candidate cancer biomarkers from formalin-fixed paraffin-embedded archival tissues. Oncogene 2007; 26:65-76.

70 Wissmann C, Wild PJ, Kaiser S, et al. WIF1, a component of the Wnt pathway, is down-regulated in prostate, breast, lung, and bladder cancer. J Pathol 2003; 201:204-212.

71 Zhu H, Mazor M, Kawano Y, et al. Analysis of Wnt gene expression in prostate cancer: mutual inhibition by WNT11 and the androgen receptor. Cancer Res 2004; 64:7918-7926.

72 Verras M, Brown J, Li X, Nusse R, Sun Z. Wnt3a growth factor induces androgen receptor-mediated transcription and enhances cell growth in human prostate cancer cells. Cancer Res 2004; 64:8860-8866.

73 Nikolova T, Wu M, Brumbarov K, et al. WNT-conditioned media differentially affect the proliferation and differentiation of cord blood-derived CD133+ cells in vitro. Differentiation 2007; 75:100-111.

74 Singla DK, Schneider DJ, LeWinter MM, Sobel BE. Wnt3a but not wnt11 supports self-renewal of embryonic stem cells. Biochem Biophys Res Commun 2006; 345:789-795.

75 Chen MS, Woodward WA, Behbod F, et al. Wnt/beta-catenin mediates radiation resistance of $\mathrm{Sca} 1+$ progenitors in an immortalized mammary gland cell line. J Cell Sci 2007; 120:468-477.

76 Katoh Y, Katoh M. Comparative genomics on PROM1 gene encoding stem cell marker CD133. Int J Mol Med 2007; 19:967-970.

77 Mizrak D, Brittan M, Alison MR. CD133: molecule of the moment. J Pathol 2008; 214:3-9.

78 Lo Celso C, Prowse DM, Watt FM. Transient activation of beta-catenin signalling in adult mouse epidermis is sufficient to induce new hair follicles but continuous activation is required to maintain hair follicle tumours. Development 2004; 131:1787-1799.

79 Shaw G, Price AM, Ktori E, et al. Hedgehog signalling in androgen independent prostate cancer. Eur Urol 2008; 54:13331343 .

80 Thalmann GN, Anezinis PE, Chang SM, et al. Androgenindependent cancer progression and bone metastasis in the LNCaP model of human prostate cancer. Cancer Res 1994; 54:2577-2581.

81 Weiss S, Dunne C, Hewson J, et al. Multipotent CNS stem cells are present in the adult mammalian spinal cord and ventricular neuroaxis. J Neurosci 1996; 16:7599-7609. 